\title{
Coping With Stereotype Threat: Denial as an Impression Management Strategy
}

\author{
William von Hippel, Courtney von Hippel, and \\ Leanne Conway \\ University of New South Wales
}

\author{
Jonathan W. Schooler \\ University of British Columbia
}

\author{
Kristopher J. Preacher \\ University of North Carolina at Chapel Hill
}

Gabriel A. Radvansky
University of Notre Dame

\begin{abstract}
Four experiments tested the hypothesis that people who are concerned with impression management cope with stereotype threat through denial. Consistent with this hypothesis, temporary employees threatened by a stereotype of incompetence (Study 1) and hostel-dwelling older adults (Study 2) were more likely to deny incompetence if they were high in impression management. African Americans (Study 3) showed a similar pattern of denying cognitive incompetence, which emerged primarily when they were interviewed by a White experimenter and had attended a predominantly Black high school. In Study 4, White students who expected to take an IQ test and were threatened by a stereotype of being less intelligent than Asians were more likely to deny that intelligence is important if they were high in impression management.
\end{abstract}

Keywords: stereotype threat, coping, denial, impression management

It is now well established that people do not perform to their potential when they feel that they are being stereotyped (Steele, Spencer, \& Aronson, 2003). Although numerous demonstrations of the disruptive effects of stereotype threat have emerged since the phenomenon was first proposed by Steele and colleagues (Spencer, Steele, \& Quinn, 1999; Steele \& Aronson, 1995), much less evidence exists about how stereotype threat makes people feel and how they cope with these feelings. The evidence that does exist suggests that, not surprisingly, stereotype threat is experienced as aversive. For example, female students respond to stereotype threat regarding mathematics with expectations of poorer performance (Cadinu, Maass, Frigerio, Impagliazzo, \& Latinotti, 2003) and associated feelings of dejection (Keller \& Dauenheimer, 2003).

One important way in which stereotype threat appears to induce aversive feelings is by diminishing the self in the eyes of others (cf. Steele, 1997). As such, one method of coping with stereotype threat would be to attempt to reestablish the perceived integrity of the self. Thus, although stereotype threat is likely to induce coping

William von Hippel, Courtney von Hippel, and Leanne Conway, School of Psychology, University of New South Wales, Sydney, Australia; Kristopher J. Preacher, Department of Psychology, University of North Carolina at Chapel Hill; Jonathan W. Schooler, Department of Psychology, University of British Columbia, Vancouver, Canada; Gabriel A. Radvansky, Department of Psychology, University of Notre Dame.

This research was supported by Grant R01 17842 from the National Institute of Aging and by grants from the Australian Research Council.

Correspondence concerning this article should be addressed to William von Hippel, School of Psychology, University of New South Wales, Sydney 2052, Australia. E-mail: w.vonhippel@unsw.edu.au strategies that are primarily intrapersonal in nature, stereotype threat is also likely to induce coping strategies that are intended for self-presentational purposes. The current evidence implicates both types of strategies. On the intrapersonal side, women who are threatened with the stereotype that they are poor at math do not show typical performance deficits if they are high in coping sense of humor (Ford, Ferguson, Brooks, \& Hagadone, 2004), suggesting that one manner of coping with stereotype threat is by using humor to reinterpret the situation as a challenge rather than a threat (see Kuiper, Martin, \& Olinger, 1993). Stereotype threat has also been shown to lead to behavioral self-handicapping (reduced practice prior to a performance; Stone, 2002) as well as claimed self-handicapping (claiming external factors that disrupted performance; Keller, 2002), both of which could be employed for either intrapersonal or interpersonal purposes (see Arkin \& Oleson, 1998).

In addition to the relatively scant evidence that addresses how people cope with stereotype threat, there is also a much broader literature that is concerned with how people cope with stigma more generally (for reviews, see Major, Quinton, McCoy, \& Schmader, 2000; Miller \& Kaiser, 2001). This literature documents a variety of strategies that people adopt when they feel stigmatized by others. Although many of these coping mechanisms may be relevant to stereotype threat, the current research focuses on a particular strategy that Miller and Kaiser (2001) categorize as an example of voluntary disengagement, specifically, that of denial. As it has been studied in the stigma literature, denial typically refers to the claim that negative self-directed outcomes are not the result of discrimination (Ruggiero \& Taylor, 1997) or that the self suffers less from prejudice and discrimination than does one's group as a whole (Crosby, 1982, 1984). In the current research we examine a 
different form of denial, whereby the individual denies the accuracy of the stereotype, at least insofar as it describes the self.

\section{Stereotype Denial as a Coping Mechanism}

When people are confronted with a threat to their self-integrity embodied in a stereotype that they believe is being applied to them, one of the simplest coping strategies is stereotype denial. In such a case, integrity of the self can be maintained either by denying the accuracy of the stereotype (a collective strategy) or by denying its self-relevance (an individualistic strategy). Although denial is likely to be maximally effective when there are no data to the contrary (e.g., when performance is not required), people are sometimes capable of denying unpleasant possibilities even in the face of contradictory evidence (Ditto \& Lopez, 1993). Additionally, when people are required to perform, they can still adopt the related strategy of denying the importance of the domain itself (Crocker \& Major, 1989; Major \& Schmader, 1998) rather than denying the accuracy or self-relevance of the stereotype (an issue we return to later).

Because there are many possible ways to cope with stereotype threat, it is likely that different strategies are adopted by different individuals (Major et al., 2000). For some people, explicit denial may be the most effective method of coping with stereotype threat, whereas for others coping might be expressed in deeds rather than words (Miller \& Kaiser, 2001). This possibility leads to the question of whether there are individual differences that might predict who is likely to cope with stereotype threat through denial and who is not.

\section{Impression Management and Denial}

One individual difference that should predict stereotype denial is impression management. Individuals who are high in impression management concerns are those who chronically deny negative self-attributes and claim positive ones (e.g., Crowne \& Marlowe, 1960; Paulhus, 1991). Thus, at first blush it might seem that people high in impression management are likely to deny incompetence regardless of whether they feel stereotype threat, leaving no room to show increased denial when they feel stereotyped. This conception of impression management appears to be inaccurate, however, as people who are high in impression management concerns do not claim to be good at everything but rather focus on presenting a positive self-image within the current context. Because different contexts lead people to focus on different aspects of the self (Markus \& Wurf, 1987), people who are trying to self-present in a positive manner should sometimes focus on competence, sometimes on sociability, and so forth. Thus, a person who is high in impression management concerns should claim competence in domains that are situationally relevant but should not necessarily claim competence in all domains.

Consistent with this logic, Lakin and Arkin (2005) found that impression management concerns, as indicated by the Impression Management subscale of the Balanced Inventory of Desirable Responding (BIDR-IM; Paulhus, 1991), showed only very weak association with claimed competence across a variety of domains, from social skills to athletic ability to emotional stability. Across nine such domains, and with over 1,000 participants, the median correlation in their sample between the BIDR-IM and self-ratings of the positive traits was .048 (a nonsignificant relationship that, incidentally, was between the BIDR-IM and self-reported intelligence).

These findings suggest that rather than claiming to be competent across the board, people high in impression management focus on domains of particular relevance or importance. One factor that could increase domain relevance is the belief that others see a domain as differentiating between groups, given that people tend to focus on domains in which they are potentially distinctive more than on domains in which they are potentially similar to others (Nelson \& Miller, 1995). Because the threat of being stereotyped in a domain causes that domain to become a source of differentiation between people (Steele et al., 2003), stereotype threat should cause a domain to become situationally relevant. As a consequence, people who are high in impression management should claim competence in a threatened domain when they may not otherwise consider it sufficiently relevant or important to warrant self-enhancement in the domain. Such selective claims of competence should result in a relationship between impression management and claimed competence under conditions of stereotype threat that does not emerge when people are not feeling threatened.

To summarize the arguments presented thus far, we have suggested that (a) stereotype threat is an aversive state that motivates a coping response on the part of the stereotyped individual; (b) of the many ways that people can cope with a threat to their selfintegrity, one of the simplest is denial; (c) because there are many ways for a person to cope with stereotype threat, not all individuals are equally likely to engage in a strategy of denial; (d) people who are chronically concerned with impression management appear more likely to rely on denial to reduce the likelihood that others will adopt a threatening view of themselves. In combination, these four premises suggest that people who are chronically concerned with impression management should be more likely to deny a threatening stereotype by denying incompetence in the stereotyped domain. Because impression management strategies of denial of incompetence and claims of competence appear to be opposite sides of the same coin (Lakin \& Arkin, 2005; Paulhus \& Reid, 1991), denial of incompetence is likely to be achieved either by exaggerating claims of competence or by denying incompetence, depending on the opportunities afforded by the situation. Consequently, the current research makes no effort to differentiate between these related strategies, although this may be a worthwhile avenue for future consideration. Rather, the primary goal of the current research is to test the hypothesis that people respond to stereotype threat with denial in a manner that is directly proportional to their chronic impression management concerns.

To test this hypothesis, we first report an experiment in which we manipulated stereotype threat and examined the impact of this manipulation on the magnitude of the relationship between impression management and denial of incompetence. We chose a group for this first study that has not yet been the focus of stereotype threat research-temporary employees. Following this experiment on temporary employees, we then report two subsequent studies examining the relationship between impression management and denial of incompetence among groups who chronically experience stereotype threat-institutionalized older adults and African Americans. After examining the relationship between denial of incompetence and impression management among these three groups, we then explore how people cope with stereotype 
threat when they know that their denial may come back to haunt them. Specifically, in Experiment 4 we examine the nature of the denial processes when people are required to perform in the stereotyped domain and thus must "put their money where their mouth is." Do such people still deny incompetence, or do they turn to other strategies? And what is the relationship between denial and performance? These issues are more fully addressed in Study 4.

\section{Study 1}

Despite the growing trend by organizations to rely on temporary workers (C. von Hippel, Mangum, Greenberger, Heneman, \& Skoglind, 1997), temporary employees do not share the same degree of esteem that is afforded to their permanent coworkers. For example, temporary employees receive lower pay and limited benefits compared with their permanent counterparts (Polivka, 1996). Additionally, although temporary employees are represented in a diversity of fields-including areas that require substantial education and training (Polivka, 1996) — managers, colleagues, and the professional community tend to regard temporary employees as less competent and lower in status than their permanent counterparts (Gallagher \& McLean Parks, 2001), and temporary employees are aware of these perceptions (Rogers, 1995). The goal of Study 1 is to rely on this stereotype of temporary employees as incompetent to test the prediction that temporary employees who are threatened by the stereotype will be likely to increase claims of competence as a function of their impression management concerns.

To achieve this goal, temporary employees completed a questionnaire that maximized stereotype threat by highlighting the stereotype that they are incompetent or minimized stereotype threat by presenting them as competent. Participants were then asked to indicate whether they have doubts about their competence in their job, following which they completed an abbreviated impression management scale.

\section{Method}

Participants. One hundred fourteen temporary employees (63 women, 51 men) registered with a national recruitment agency and residing in Sydney, Melbourne, or Brisbane, Australia completed the questionnaire on a volunteer basis. The average age of participants was 27 years, with a range from 19 to 69 years $(S D=9.35)$. Fifty-three percent of the participants had received a tertiary education, $20 \%$ had earned a technical degree, $19 \%$ were high school graduates, and the remainder had completed some high school. Participants had been working as temporary employees from as little as 1 week to a maximum of 15 years, with the average time being 1 year and 7 months $(S D=2.63$ years). Participants worked in a variety of industries, but the primary industries were market research (24.5\%); accounting, banking, finance or insurance (20.9\%); telecommunications (13.6\%); and retail sales or customer service (12.7\%).

Potential participants were recruited for the experiment when they arrived at their temporary employment agency for an assessment interview (concerning possible placement at a company). While they waited for their interview, they were informed by the human resources manager that there was a brief research project underway that was independent of the selection process and in which they were invited to participate. Participants were offered a selection of candies in appreciation of their time, and they completed the brief questionnaire in the agency waiting room.

Materials and procedure. To manipulate stereotype threat, participants first read descriptions of temporary employees that were ostensibly written by different managers. Three opinions were presented and these were all framed negatively in the threat condition and positively in the no-threat condition. For example, the first manager's opinion in the threat condition was

I find temporary employees under-skilled. Many don't have the necessary training to perform effectively and productively in their jobs, so we often have to train them. This uses up our resources. The worst thing is, when they leave, we lose the training we invested in them.

In the no-threat condition this manager wrote

Temporary employees are quick to adjust to a new situation. They come in knowing they have a job to do and a short time to do it, so they have to be adaptable and fast learners. Most of them are very good at this.

Participants were then informed that to help us learn about the attitudes temporary workers have toward their job, we would like them to indicate their agreement or disagreement with a series of statements designed to measure attitudes and abilities. Among several filler questions, participants responded to the critical denial item, "I have doubts that I am competent in my job." Their response was provided on a 5-point scale anchored by strongly disagree (1) and strongly agree (5) but was recoded so that higher numbers indicate greater denial.

Participants then provided demographic information assessing their age, gender, ethnicity, industry of their most recent assignment, and how long they have been engaged in temporary work. Participants then completed a modified version of the BIDR-IM. Instructions to the scale indicated that it was intended to assess how temporary employees deal with sensitive situations at work and in life in general. For the sake of brevity (as participants were completing the scale while waiting to see the HR manager), participants were asked to respond to only 9 of the 20 items from the original scale, including items asking if they sometimes tell lies and if they have some pretty awful habits (denial of these items is indicative of impression management concerns). Additionally, the original 7-point scale was simplified to a 3-point scale anchored by the phrases not true (1), somewhat true (2), and very true (3). After completion of the survey, participants were debriefed and thanked for their time.

\section{Results}

Prior to conducting the primary analyses, an analysis of variance (ANOVA) confirmed that the stereotype threat manipulation had no discernable effect on responses to the Impression Management scale. Participants in the threat condition showed a mean response on the BIDR-IM that was functionally equivalent $(M=2.12$, $S D=2.29)$ to participants in the no-threat condition $(M=2.13$, $S D=2.28, F<1, n s)$. Similarly, an ANOVA comparing denial of doubt in the threat $(M=2.00, S D=.94)$ and no-threat conditions $(M=2.08, S D=1.02)$ failed to reveal any differences $(F<1, n s)$. Reliability analysis of the BIDR-IM was then conducted. Perhaps because of its abbreviated form or the simplified 3-point response scale, the Impression Management scale suffered from low interitem consistency $(\alpha=.56)$.

To test the primary prediction that impression management predicted denial of doubt among threatened but not among nonthreatened participants, correlations were computed between denial of doubt and the BIDR-IM. For these correlations, we included duration as a temporary employee as a covariate, to control for any effects that length of experience as a temporary employee has on denial of doubt. 
Despite the low reliability of the BIDR-IM, this analysis revealed that the BIDR-IM was correlated with denial of doubt (partialing out duration) in the threat condition, $\operatorname{pr}(49)=.41, p<$ .001 , but not in the no-threat condition, $\operatorname{pr}(65)=.04$, ns. Comparison of these partial correlations revealed that they were significantly different from each other, $\chi^{2}(1, N=114)=4.24, p<$ .05 . To ensure that these results were not influenced by the low reliability of the BIDR-IM in this or subsequent studies, we also conducted latent variable analyses for each of the experiments; they are reported after Study 4.

\section{Discussion}

These data provide support for the hypothesis that some people cope with stereotype threat via denial. When temporary workers were told that managers think they are incompetent, employees who are particularly concerned with impression management were more likely to deny having doubts about their ability than were employees who are not as concerned with impression management. Temporary workers who were told that managers think they are competent, in contrast, showed no such relationship between impression management and denial of doubt. It is worth noting in this regard that this no-threat condition actually involved an affirmation, rather than simply no threat, as temporary employees were told that managers regard them as fast learners. This affirmation may well have attenuated the relationship between impression management and denial, as self-affirmation has been shown to reduce stereotype threat (Schimel, Arndt, Banko, \& Cook, 2004). Such an outcome was probably beneficial in this experiment, as the workplace context in which the study was conducted might otherwise have been sufficiently threatening to temporary employees to cause them to show a relationship between denial and impression management. Nevertheless, it would be useful to demonstrate that threat increases the relationship between denial and impression management compared with baseline conditions. For this reason, the remaining studies did not involve any affirmation of ability.

In addition to providing initial evidence that people cope with stereotype threat via denial, the current data also extend stereotype threat research to a new population. Although there is a substantial literature in organizational psychology on temporary employees and the problems and opportunities associated with temporary employment (see Gleason, in press), social psychologists have not yet extended research or theorizing to this group. The current research suggests that temporary employment might be a fruitful domain for studying stereotyping and prejudice, in part because the consequences have such important implications for temporary employees and their livelihood.

Study 1 provided evidence that inducing stereotype threat leads people who are high in impression management concerns to deny doubts about their competence. Such acute manipulations of stereotype threat are common and powerful (see Steele et al., 2003), but the literature also provides evidence that many people feel chronically threatened by various stereotypes regarding character and ability (e.g., Steele \& Aronson, 1995). The goal of Study 2 was to extend the current results to a population that is chronically stereotype threatened.
Study 2

Being perceived as having poor cognitive functioning is potentially threatening for many people, but this threat is exacerbated among many older adults, for whom some aspects of cognitive decline are a daily concern. In support of this possibility, Levy and her colleagues have shown that priming stereotypes of poor cognitive ability leads older adults to experience increases in cardiovascular stress (Levy, Hausdorff, Hencke, \& Wei, 2000) and disruptions in performance (Levy, 1996). These data suggest that concerns about cognitive failure are both threatening and chronically accessible for many older people.

If concerns about cognitive failure are chronically accessible for some older adults, then the mere mention of cognitive failure should be sufficient to raise the specter of the stereotype (Steele \& Aronson, 1995). Consequently, in Study 2 rather than threatening older adults, we simply asked them to report on their cognitive failures. As Steele and Aronson (1995) have shown, such questioning should be stereotype threatening for individuals who are chronically confronted with the threat of cognitive decline.

The goal of Study 2 was to test the possibility that older adults would respond to the threat of cognitive failure by employing the strategy of denial, in a manner similar to threatened temporary employees in Study 1. However, rather than compare younger and older adults, this study sought to compare older adults who should be particularly susceptible to stereotype threat regarding cognitive ability with older adults who should be relatively resistant to stereotype threat regarding cognitive ability. Specifically, in Study 2 participants were either residents of elder hostels or were community-dwelling older adults who reported involvement in a variety of activities (e.g., participants were recruited from university courses offered to retired individuals, art classes, etc.).

Because older adults often move into elder hostels when they no longer feel mentally or physically capable of maintaining their own domicile $(77.5 \%$ of our sample reported this as the reason for moving into a hostel), it is likely that on average, older adults who live independently will have better cognitive abilities than those in elder hostels. Older adults living in hostels should thereby be more threatened by the stereotype of (and possibly their experience with) cognitive decline and thus should show a stronger relationship between impression management and denial of cognitive failures than active older adults living in the community. The goal of Study 2 was to test this hypothesis.

To measure denial, Study 2 relied on the Cognitive Failures Questionnaire (CFQ; Broadbent, Cooper, Fitzgerald, \& Parkes, 1982). This measure differs from the denial measure used in Study 1 in that it requests participants to report on minor mental lapses in memory and attention. Thus, the measure of mental competence was more closely aligned with absentmindedness than with intelligence. Such lapses should not be particularly threatening for most adults, but they should be threatening for some older individuals, as absentmindedness among older adults is perceived as evidence of cognitive decline and thus has much greater threat potential. For this reason, the CFQ is expected to be more threatening to hosteldwelling older adults than to active, community-dwelling older adults. A measure of memory span was also included to assess whether cognitive performance differed in the two samples of older adults and whether self-reported cognitive failures correlated with actual memory performance. 


\section{Method}

Participants. Thirty-nine older adults (age 64 to 95 years, $M=76$, $S D=7.4 ; 34$ women, 5 men) were recruited from the Sydney community on the basis of their participation in activities outside the home. Forty older adults (age 65 to 95 years, $M=86, S D=6.0 ; 33$ women, 7 men) were recruited from Sydney area elder hostels. Participants in both communities were offered 20 Australian dollars ( $\sim \$ 15$ US) for participation in a study of social behavior.

Measures and procedure. Participants were tested individually in their homes or common areas of their community center. The experimenter began by requesting demographic information, such as age and retirement status, and then orally presented participants with 21 items of the 25 -item CFQ. For each item participants indicated on a 5-point scale, anchored by never (1) and very often (5), how frequently they had experienced various failures of memory, perception and motor functioning in the last 6 months. An example item reads, "In the last six months, how often did you forget why you went from one part of your house or apartment to the other?" The four items that were not included all referred to activities that were no longer relevant for hostel residents (e.g., "In the last six months, how often did you fail to notice signposts on the road?"; because none of the hostel residents drive, they reported that they do not look for signposts).

Participants were then given a 12 -item modified version of the BIDRIM. Despite the low reliability that emerged with the abbreviated scale in Study 1, pretesting with hostel residents revealed that the 7-point scale was occasionally confusing, and so it was simplified to "true" or "false". Additionally, pretesting also revealed that a number of the items were more relevant to younger than older adults, particularly those residing in elder hostels (e.g., "I sometimes drive faster than the speed limit"), and so the original scale was shortened to a 12-item "true"/"false" scale for use in the current study.

To provide an indicator of cognitive ability, participants then completed a memory span measure, which required them to retain in short-term memory a list of words that increased from three to eight words per set. Each word list was orally presented by the experimenter at a pace of one word per $1.5 \mathrm{~s}$, and at the end of the list, participants were asked to repeat as many of the words as possible, in any order. Participants were also given a measure of vocabulary, which was a shortened version of the Shipley Vocabulary Test (Zachary, 1986), in which every fourth item from the original test was chosen for presentation. For this test, each target word was presented in 48-point font, and participants were required to choose which of four possible words, also written in 48-point font, was most similar in meaning to the target word. Participants were then debriefed and thanked for their participation.

\section{Results}

Prior to testing our hypotheses, reliability analyses were conducted. The CFQ showed acceptable interitem consistency $(\alpha=$ $.80)$, but the abbreviated BIDR-IM showed poor interitem consistency $(\alpha=.58)$. Although the CFQ was uncorrelated with age, $r=$ $-.04, p>.65$, the BIDR-IM was positively correlated with age, $r=.41, p<.001$. Because hostel dwellers were older on average than community dwellers, analyses of covariance were conducted to compare levels of CFQ and BIDR-IM across samples, with age as a covariate. These analyses revealed a marginal effect of sample type on the BIDR-IM, $F(1,76)=2.91, p<.10$; age covariate, $F(1,76)=16.01, p<.001$, such that participants living in hostels endorsed more of the impression management items (adjusted $M=71 \%, S D=16 \%$ ) than did participants living independently (adjusted $M=64 \%, S D=17 \%$ ). Similarly, sample type had a marginal effect on the CFQ, $F(1,76)=3.64, p=.06$; age covariate, $F(1,76)=.16, p>.65$, such that participants living in hostels reported fewer cognitive failures (adjusted $M=2.17$, $S D=.48$ ) than did participants living independently (adjusted $M=2.41, S D=.38$ ).

To assess whether differences emerged between hostel and community dwellers in memory span and vocabulary, we again conducted analyses of covariance with age as a covariate. These analyses revealed a marginal effect of sample on vocabulary, $F(1$, $76)=3.64, p=.06$; age covariate, $F(1,76)=6.40, p<.02$, such that participants living in hostels answered fewer of the items correctly (adjusted $M=69 \%, S D=20 \%$ ) than participants living independently (adjusted $M=78 \%, S D=15 \%$ ). Similarly, sample type had a significant effect on the total number of items participants recalled from the word span trials, $F(1,76)=17.46, p<$ .001 ; age covariate, $F(1,76)=8.68, p<.01$, such that participants living in hostels had poorer memory span (adjusted $M=16.99$, $S D=4.30$ ) than participants living independently (adjusted $M=$ $21.47, S D=3.67)$. The CFQ failed to correlate with memory span or vocabulary, $r \mathrm{~s}<.11, p \mathrm{~s}>.35$ (even when analyzed as a latent variable), and memory span and vocabulary were positively correlated, $r=.36, p=.001$.

Similar to Study 1, we then examined partial correlations between the BIDR-IM and the CFQ, in this case controlling for age. Consistent with predictions, this analysis revealed that the BIDR-IM was correlated with the CFQ (partialing out age) among participants living in hostels, $p r=-.57, p<.001$, but not among participants living in the community, $p r=-.20, n s$. Additionally, these partial correlations were significantly different from each other, $\chi^{2}(1, N=79)=3.86, p<.05$.

\section{Discussion}

The results of Study 2 provide additional support for the hypothesis that people high in impression management concerns rely on denial as a coping strategy when confronted with the threat of negative stereotypes. Specifically, older adults who were living in an elder hostel showed a stronger relationship than did those living in the community between impression management and denial of cognitive failures. Consistent with the possibility that the threat of cognitive failures among hostel dwellers is in part associated with actual cognitive decline, hostel dwellers had lower memory span scores than did community dwellers, even after we controlled for age differences.

These results suggest that the possibility of cognitive decline is particularly threatening for older adults who live in elder hostels. Perhaps some of this threat is induced by the fact that residents of elder hostels are regularly reminded of the assistance they require in daily living. As such, these results also suggest that priming community-dwelling older adults with negative images of aging might cause cognitive failures to be experienced as more threatening. Thus, it seems likely that the priming manipulations used by Levy and her colleagues (Levy, 1996; Levy et al., 2000) might also lead to an increased association between the CFQ and impression management among older individuals who live independently in the community. This remains a question for future research.

It should also be noted that the current study differs from previous research on stereotype threat in that not only are institutionalized older adults threatened by a stereotype of cognitive decline, but most are probably threatened by the reality of cognitive decline as well. That is, institutionalized older adults may 
often be more concerned with their daily experiences with cognitive decline than they are with the possibility that others are stereotyping them as cognitively incapable. Despite this possibility, the current results nevertheless indicate that institutionalized older adults who are concerned with impression management are more likely to deny their cognitive failures. This finding suggests that however threatening the daily reality of cognitive decline might be for institutionalized older adults, there is additional threat associated with the possibility that others might view them as cognitively incompetent. Thus, although the current results might be a function of both group stereotypes and individual daily experiences, the fact that impression management concerns predicted denial suggests that stereotypes and the consequent perceptions of others have their own unique potential for threat.

Like Study 1, the current results also extend the stereotype threat literature to a new population. The impact of stereotype threat on cognitive performance has been documented among older adults (Hess, Auman, Colcombe, \& Rahhal, 2003), but there is no current stereotype threat research comparing community dwelling with institutionalized older adults. The current findings provide evidence that group subtypes that are the basis of strong stereotypes (see Brewer, Dull, \& Lui, 1981) also play an important role in stereotype threat. Nevertheless, despite the advantages of demonstrating stereotype threat with new populations, there is the parallel disadvantage that there is no previous research confirming the presence of stereotype threat among these groups or the manner in which it is typically induced or manifested. Thus, the goal of Study 3 was to turn to a domain where a great deal is known about stereotype threat, in an effort to provide stronger support for the hypothesis regarding denial as a coping strategy. Study 3 also had the goal of exploring whether denial was intended primarily for self-presentational purposes.

\section{Study 3}

Similar to Study 2, in Study 3 we relied on the fact that the stereotype of intellectual inferiority is chronically accessible for African Americans, and the mere mention of intellectual achievement should lead to stereotype threat (Steele \& Aronson, 1995). Thus, rather than telling African Americans that they are intellectually inferior, we simply asked Black and White university students how intelligent they are. As Steele and Aronson (1995) have shown, this question should be stereotype threatening for Black but not White students. According to predictions regarding denial as a coping strategy, this procedure should result in a relationship emerging between impression management and claims of intelligence that is stronger among Black students than it is among Whites. In contrast, because Blacks are stereotyped to be athletic, such a differential relationship should not emerge between impression management and claims of athleticism. Consequently, this relationship was also examined to ensure that the relationship between claims of competence and impression management is not higher in general among Blacks than among Whites.

Additionally, some participants were run through the procedure by a Black experimenter and some by a White experimenter. If denial of incompetence serves a self-presentational purpose in the face of stereotype threat, then a relationship should only emerge between impression management and denial among Black students in the presence of a White experimenter. Furthermore, because stereotype threat from fellow White students is a very familiar experience for many Black students, it seemed likely that this self-presentational strategy might be most common among those Black students who are least experienced in coping with it. Thus, we also asked students about the racial composition of their high school, under the assumption that Black students from predominantly Black schools will be least experienced in coping with such stereotype threat and thus most likely to show the strategy of denial. We also asked participants about the racial composition of their neighborhood, to ensure that it was a lack of familiarity interacting with Whites in a school setting that moderated the effect, rather than a simple lack of familiarity interacting with Whites in general.

\section{Method}

Participants. One hundred thirty-two African Americans (88 women, 44 men) and 207 non-Hispanic Whites (83 women, 124 men) participated for partial fulfillment of their course requirements for introductory psychology. Participants were recruited by telephone from a list of nearly all the students enrolled in introductory psychology at Ohio State University during a single autumn quarter, from which all African American students were contacted and a subset of White students was contacted. These participants were tested individually in a computer-equipped laboratory through a larger study (W. von Hippel, Hawkins, \& Schooler, 2001, Study 3 ), but the current method and results sections focus only on the questions relevant to denial as a coping strategy. The measures and analyses described here were not reported in W. von Hippel et al. (2001), nor were the results reported here influenced by any of the procedures involved in the full experiment.

Materials and procedure. To assess claims of competence, participants were randomly assigned to be asked by either a Black or White experimenter of their same gender how intelligent they are and how athletic they are compared with other students at Ohio State University. Participants responded on 7-point scales anchored by much less (1) and much more (7) Participants then completed the full version of the BIDR-IM and then estimated the percentage of their high school and their neighborhood that was of the same race as themselves. After completing other measures unrelated to the current research, participants were fully debriefed.

\section{Results}

Prior to testing our hypotheses, we conducted reliability analyses. The impression management scale showed acceptable interitem consistency $(\alpha=.81)$. An ANOVA revealed no differences in impression management scores $(M=3.69, S D=.95$ vs. $M=$ 3.63, $S D=.89)$ or claimed intelligence $(M=4.96, S D=.89$ vs. $M=5.04, S D=.86)$ between Blacks and Whites, respectively $\left(F_{\mathrm{S}}<1, n s\right)$. In contrast, Whites claimed greater athleticism $(M=$ $4.38, S D=1.49)$ than did Blacks $(M=3.67, S D=1.81), F(1$, $337)=15.34, p<.001$.

To test the primary prediction that impression management predicted claims of intellectual competence among African Americans but not among Whites, correlations were computed between claims of competence and the BIDR-IM. Consistent with predictions, these analyses revealed that the BIDR-IM was correlated with self-reported intelligence among African Americans, $r(132)=.29, p<.001$, but not among Whites, $r(206)=-.01, n s$. Comparison of these correlations revealed that they were significantly different from each other $(z=2.74, p<.01)$. In contrast, the BIDR-IM was uncorrelated with self-reported athleticism 
among both African Americans, $r(132)=.07, p>.40$, and Whites, $r(207)=-.08, p>.25{ }^{1}$

Effects of race of experimenter, high school, and neighborhood. To test the hypothesis that denial is used as a self-presentational strategy among those who are high in impression management, these correlations were then examined separately among participants who had a Black or a White experimenter and as a function of the race of their high school and neighborhood. Consistent with predictions, the correlation between self-reported intelligence and impression management was significant among African American participants when the experimenter was White, $r(71)=.27, p<$ .03 , but not when the experimenter was Black, $r(61)=.17, p>$ .15 , although the difference between these correlations was not significant, $z=0.61, p>.50$. With White participants, no difference was predicted as a function of race of experimenter, and the correlations were similar whether the experimenter was Black, $r(121)=-.03, p>.75$, or White, $r(85)=.04, p>.70$.

Despite the fact that race of experimenter did not lead to a significant difference in the correlations, it is nevertheless possible that the effect documented among African American participants was driven primarily by those who had a White experimenter and attended predominantly Black high schools. To test this possibility, race of high school was dichotomized to be either greater than $50 \%$ Black or $50 \%$ Black or less, and the correlations between self-reported intelligence and BIDR-IM were then examined separately by race of participant, race of experimenter, and racial composition of the participant's high school. This analysis revealed the predicted pattern of correlations, such that the BIDR-IM predicted self-reported intelligence only among African American participants who had a White experimenter and had attended a predominantly Black high school, $r(20)=.64, p<.03$. This correlation was significantly greater than the correlation that emerged among African American participants who had a White experimenter but had attended a high school that was not predominantly Black, $r(49)=.12, p>.50, z=2.27, p<.03$. This correlation was also significantly greater than the correlation that emerged among African American participants who had a Black experimenter and had attended a high school that was not predominantly Black, $r(34)=.12, p>.50, z=2.11, p<.04$, but was not significantly greater than the relationship that emerged among African American participants who had a Black experimenter and had attended a high school that was predominantly Black, $r(25)=$ $.29, p>.15, z=1.42, p>.15$. Because so few White participants had attended a high school that was predominantly Black (6 of the 207 White students in the study), this analysis could not be conducted with the White participants.

When this analysis was repeated among African Americans with race of neighborhood as the moderating variable, this pattern of results did not emerge. Rather, African American participants who had a White experimenter showed a significant correlation between self-reported intelligence and the BIDR-IM when their neighborhood was not predominantly Black, $r(36)=.37, p<.03$, but not when their neighborhood was predominantly Black, $r(34)=.17, p>.30$. These correlations did not differ from one another, $z=0.87, p>$.35. Among African American participants who had a Black experimenter, the correlations between selfreported intelligence and BIDR-IM were not significant when their neighborhood was predominantly Black, $r(32)=.22, p>.20$, or not, $r(29)=-.03, p>.85$.

Examining the locus of the impression management effect. There is one final issue that can be tentatively addressed with this data set. We have argued that the correlation between impression management and claims of competence is evidence that people high in impression management concerns are denying incompetence by exaggerating their ability, but it could just as easily be the case that people low in impression management are accepting incompetence by understating their ability. The correlation between impression management and self-reported ability does not allow one to distinguish between these two interpretations. Because the data set used in Study 3 contains measures of performance, however, it is possible to see who is more accurate in their self-report-those who are high in impression management or those who are low. According to our interpretation of the data, African Americans who are low in impression management should more accurately report their ability than should African Americans who are high in impression management (whereas there should be no difference for Whites).

As an initial test of this hypothesis, two measures of performance were garnered from the Study 3 data set (from W. von Hippel et al., 2001). One measure was self-reported high school GPA and the other was registrar-reported college entrance exams (students took either the ACT or SAT, and thus they were standardized within type and treated interchangeably). Because there were missing data in the registrar database, we standardized high school GPA and combined ACT/SAT with high school GPA to have a data set that was more complete but did not rely entirely on self-report (ACT/SAT correlated with high school GPA at $r(111)=.33, p<.001$ among African Americans and $r(197)=$ $.39, p<.001$ among Whites).

Consistent with predictions, self-reported intelligence was correlated with academic performance among African Americans whose impression management scores were below the median, ${ }^{2} r(60)=.31$, $p<.02$, but not among African Americans at or above the median, $r(71)=.02, p>.85$, although these correlations were only marginally different from each other, $z=1.66, p<.10$. In contrast, Whites showed a significant relationship between self-reported intelligence and academic performance whether they were below the median,

\footnotetext{
${ }^{1}$ Although Whites are not stereotyped to be athletic, they are also not stereotyped to be unathletic in the same manner that Blacks are stereotyped to be unintelligent. Consistent with this notion, White participants in the current sample reported that they felt that Whites are stereotyped as slightly above the scale midpoint in athleticism, $M=4.17, t(204)=1.97, p=.05$ $(1=$ stereotyped as not at all athletic, $7=$ stereotyped as very athletic $)$, whereas Blacks reported that they felt that Blacks are stereotyped as below the scale midpoint in intelligence, $M=3.39, t(131)=-4.49, p<.001$ $(1$ = stereotyped as not at all intelligent, 7 = stereotyped as very intelligent).

${ }^{2}$ A median split of continuous data represents poor statistical practice with many associated costs (MacCallum, Zhang, Preacher, \& Rucker, 2002), but there is no alternative technique available to test the current hypothesis. Despite the fact that moderated regression is commonly used to test for such differences between relationships, this is a misuse of the technique, as moderated regression is properly suited for assessment of interactions of form rather than interactions of degree (Arnold, 1982).
} 
$r(102)=.26, p<.01$, or at or above the median, $r(103)=.46, p<$ .001 , in impression management.

\section{Discussion}

Study 3 provides additional evidence of stereotype denial as a coping strategy. In Study 3 African Americans who were highly concerned with impression management were more likely than African Americans who were relatively unconcerned with impression management to claim to be intelligent. Furthermore, this relationship was particularly likely to emerge when the experimenter was White and when the African American participants had attended predominantly Black high schools. Growing up in a predominantly Black neighborhood did not moderate the relationship in the same manner as did attending a Black high school. This pattern of findings suggests that the relationship between impression management and denial of incompetence is audience specific and sensitive to contextual familiarity with the audience, thereby implicating a communicative function for stereotype denial. This pattern of findings did not emerge among Whites and did not emerge with regard to claims of athleticism.

Study 3 also provides tentative evidence that the relationship between impression management and denial of incompetence reflects exaggeration or compensation (see Miller, Rothblum, Felicio, \& Brand, 1995) among people high in impression management rather than excessive modesty among people low in impression management. Specifically, a relationship between selfreported intelligence and academic performance emerged only among Blacks low in impression management, suggesting that self-report was distorted among Blacks high rather than low in impression management. Although the necessity of relying on a median split to test this hypothesis emphasizes the need for replication, the findings are consistent with predictions.

In combination, Studies 1-3 provide clear support for the hypothesis that when people feel threatened by a stereotype, those who are concerned with impression management cope with the threat by denying incompetence in the threatened domain. Despite this consistency across studies, however, none of the studies addresses how people will respond to stereotype threat when they know they will have to perform in the stereotyped domain. When no performance is required, denying incompetence is a low-cost and low-risk strategy, as claims of ability are unlikely to come back to haunt a person. In contrast to this situation, most stereotype threat studies (and many real-life situations) demand performance in the stereotyped domain. This difference leads to the question of how people will cope with stereotype threat when they know that their performance will be assessed.

If people worry that their claims of competence might backfire and make them look foolish, they can still cope with the threat with denial by denigrating the importance of the domain itself (Crocker \& Major, 1989; Major \& Schmader, 1998). No matter how one performs, asserting that the domain is unimportant has the potential to protect the individual, as this strategy communicates that the person is not invested in performance and probably does not try as hard. If the person then fails, esteem is protected by the inference that he or she probably could have succeeded had he or she tried harder. If the person then succeeds, ability inferences are likely to be augmented under the assumption that less effort and investment nevertheless led to a positive outcome. This possibility suggests that individuals who are high in impression management can respond to stereotype threat with denial, even when they know their competence will be tested, simply by denying the importance of performance in the domain. The goal of Study 4 was to test this hypothesis.

\section{Study 4}

To examine strategies of coping with stereotype threat when performance is imminent, White participants in Study 4 were presented with an IQ test. Half of the participants were told that Asians outscore Whites on the test, and the other half were told that the test is "culturally fair" and no differences emerge in performance across different ethnic groups, nationalities, social classes, and so forth. Participants were then asked, prior to taking the test, how intelligent they are and how important it is to be intelligent. Participants then completed a subset of difficult problems from Raven's Advanced Progressive Matrices (Raven, Court, \& Raven, 1985), allowing an assessment of their overall score and how many problems they attempted. According to predictions, participants high in impression management should denigrate the importance of being intelligent when threatened but should not do so when they are not threatened. Such a relationship should not emerge with claimed intelligence, as the possibility of performing poorly on the test should make this strategy too risky for those concerned with impression management. Furthermore, impression management was not expected to relate to performance on Raven's matrices, as the coping strategy of denial was not expected to underlie performance differences.

\section{Method}

Participants. Fifty-six White students (50 women, 6 men) at the University of New South Wales participated for partial fulfillment of introductory psychology course requirements.

Measures and procedure. Participants were tested individually. The experimenter began by explaining that the experiment was concerned with the relationship between personality and intelligence, and that they would be asked to complete some personality scales, some items measuring their proclivities and interests, and an IQ test. Participants who were randomly assigned to the stereotype threat condition were told (by a White female experimenter), "You probably will not be surprised to hear that Asians tend to perform better than Whites on tests of intelligence. For this reason, we need you to indicate your ethnicity so that we can score people's performance separately by different racial groups." Participants who were assigned to the control group were told that the particular test used in this research was chosen because it was culturally fair, and did not show differences as a function of race, nationality, or social class. Additionally, their form did not request information regarding their race.

All participants then completed a questionnaire concerning various interests and talents, included in which was an item asking how intelligent they are compared with other University of New South Wales students, and an item asking how important it is to them to be intelligent. The intelligence question was answered on a 7-point scale ranging from 1 (much less) to 7 (much more), and the importance question was answered on a 7-point scale ranging from 1 (not at all important) to 7 (very important). Participants were then given the original 20-item version of the BIDR-IM, following which they had 15 min to complete a 16-item version of Raven's Matrices that included primarily high-difficulty items. Participants were then debriefed and dismissed.

\section{Results}

Prior to examining our hypotheses, reliability analyses were conducted. The BIDR-IM showed modest interitem consistency 
$(\alpha=.67)$. An ANOVA revealed no differences in impression management scores $(M=4.12, S D=.68$ vs. $M=4.19, S D=$ $.60)$, importance of being intelligent $(M=5.81, S D=1.00$ vs. $M=5.72, S D=1.03)$, or self-reported intelligence $(M=4.11$, $S D=.85$ vs. $M=3.93, S D=1.03)$ between threat and no-threat conditions, respectively $(F \mathrm{~s}<1, n s)$.

Similar to Studies 1 to 3 , analyses revealed that the BIDR-IM was correlated with importance of being intelligent in the threat condition, $r(27)=-.52, p<.01$, but not in the no-threat condition, $r(29)=.00, n s$. These correlations were significantly different from each other $(z=2.04, p<.05)$. In contrast to these findings with importance of being intelligent, self-reported intelligence failed to show a differential relationship with impression management as a function of stereotype threat. The BIDR-IM was uncorrelated with self-reported intelligence in both the threat $(r=$ $-.14, p>.45)$ and no-threat $(r=.31, p>.10)$ conditions (and the nonsignificant difference between the correlations was opposite that found in the earlier studies).

The next stage in the analyses was to assess whether participants' performance suffered when they were in the stereotype threat condition. Consistent with prior stereotype threat research, participants showed a lower mean score on Raven's Matrices when they were threatened by the stereotype $(M=36.2 \%, S D=25.6 \%)$ than when they were not $(M=47.7 \%, S D=21.8 \%)$, although this difference obtained only marginal significance, $F(1,52)=3.18$, $p=.08$. Analyses also revealed that participants completed more problems when they were threatened by the stereotype $(M=$ $85.6 \%, S D=13.5 \%)$ than when they were not $(M=75.9 \%, S D=$ $16.0 \%), F(1,52)=5.80, p=.02$. Neither mean score nor the number of problems attempted on Raven's Matrices correlated with impression management, self-reported intelligence, or selfreported importance of being intelligent $(|r s|<.19, p s>.15)$.

Because the problems on the Raven's are so difficult, it may not be in participants' best interest to attempt all of them, as their efforts may be better spent focusing on just a few. If threatened individuals score lower because they attempt more problems, the marginally significant difference in performance should be mediated by the difference that emerged in the number of problems attempted. As can be seen in Figure 1, a regression-based path analysis provided support for this prediction. Consistent with the ANOVA results, the direct path from threat to performance on Raven's Matrices was marginally significant when no mediator was included in the model and was reduced to nonsignificance

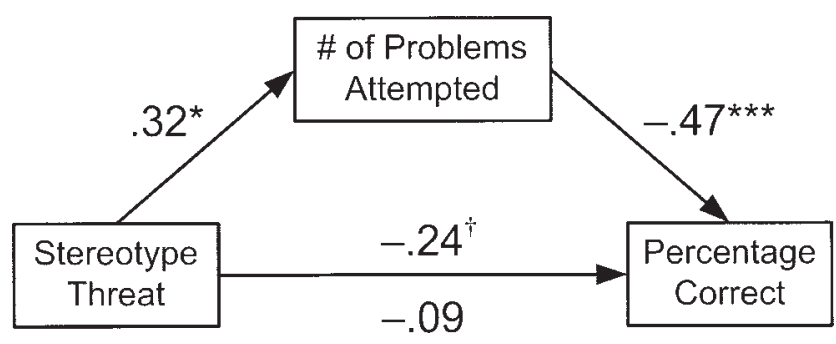

Figure 1. Path diagram of regression-based causal model used in Study 4. The coefficient above the path from stereotype threat to percentage correct represents the direct effect without the mediator in the model, and the coefficient below the path represents the direct effect when the mediator is included in the model. $\uparrow p<.10 .{ }^{*} p<.05$. *** $p<.001$. when the number of items attempted was included as a mediator. A Sobel test revealed that this mediated pathway, from stereotype threat to number of items attempted to final score, was significant, $z=2.03, p<.05$.

\section{Discussion}

The results of Experiment 4 provide further evidence for how people cope with stereotype threat through denial. As in Studies $1-3$, participants who were most concerned with impression management were most likely to rely on denial to cope with the threat of the stereotype. This experiment extends the prior studies by demonstrating a different pathway for denial when people are required to perform in the stereotype-relevant domain. Rather than denying incompetence and thereby risking having their nose rubbed in a poor performance immediately afterward, participants concerned with impression management instead chose to deny that the domain itself is important. This strategy has the advantage that these participants were able to distance themselves from a potentially poor performance by suggesting that the stereotyped domain is not self-relevant. Whether such a strategy would be prevalent and/or effective among highly identified individuals remains to be seen, however, as such claims may ring hollow among people highly invested in domain (participants in the current study were not preselected for high levels of identification).

This strategy of denying the importance of a domain in which one might perform poorly is reminiscent of impression management strategies noted by Tesser and Paulhus (1983), who found that people claim that tasks at which they succeed are more important than tasks at which they fail. In this case, however, the strategy appears to be operating in advance of a possible failure rather than in response to a previous failure. Thus, denial of importance in the current experiment might be seen as an example of proactive coping, whereby people prepare for the possibility of failure by minimizing its psychological consequences (Wilson, Wheatley, Kurtz, Dunn, \& Gilbert, 2004).

One derivation from these results is the prediction that when people believe they will not be tested in a threatened domain they should deny incompetence in the domain, whereas when people believe they will be tested in a threatened domain they should deny importance of the domain. This distinction could prove to be important, as it may predict when people will disidentify with a domain, given that disidentification is essentially the chronic denial of domain importance (see Steele, 1997). Thus, the current results suggest that domains that regularly demand performance from threatened individuals, such as academic performance in school or athletic performance in the gym, may be most likely to lead to disidentification as a coping strategy. In such cases, because it is too risky to claim to be good at something when failure may be imminent, those individuals who are most concerned about impression management may be most likely to deny the importance of the domain. If this denial of domain importance comes to be believed by the individual engaged in the denial (either through self-perception, necessity, etc.), the long-term outcome will be domain disidentification. This possibility that people high in impression management who are chronically required to perform in stereotype threatened domains are likely to become disidentified would seem to be a worthwhile avenue for future research. 
Finally, it is worth noting that the current results also provided some evidence for the typical performance deficits that are documented under stereotype threat. Participants who were threatened by the stereotype that Asians outperform Whites showed a lower score on a widely used IQ test than did participants who were not threatened by this stereotype. Although this effect was only marginally significant, it should be noted that no covariates were available to partial out prior differences in preparation or ability (as is typically done in stereotype threat research). Furthermore, this effect of stereotype threat on performance was mediated by differences in the number of problems attempted. Participants who were threatened adopted a strategy of attempting to solve problems that were apparently better left untouched. As a consequence of this change in behavior, their mean score on the test was diminished.

Consistent with the notion that different people adopt different strategies for coping with stigma (Major et al., 2000), the effect of stereotype threat on problems attempted on Raven's Matrices was not influenced by impression management. Rather, this seems to be a strategy unrelated to this particular individual difference. Although it is unclear from the current data whether this change in behavior was an attempt to cope with stereotype threat or an unintended by-product of other aspects of the situation, one interpretation is that the attempt to solve more problems represents a behavioral manifestation of denial, whereby people attempted to achieve more to prove the stereotype wrong. Nevertheless, this remains a question for future research, as various goals or psychological states could be implicated in this behavior.

\section{Latent Variable Analysis}

Because low reliability was a concern in three of the studies, a latent variable analysis was used to supplement the previous analyses. Researchers commonly use structural equation modeling (SEM) when testing hypotheses involving scales with less than ideal reliabilities, as the separation of common and unique variance implicitly corrects the correlation of interest for attenuation. An additional benefit of SEM is that it permits computation of indices of model fit. We used the Mx software package to specify and estimate all models (Version 1.3.65; Neale, Boker, Xie, \& Maes, 2003).

\section{Data Preparation}

To take advantage of SEM's ability to partition variance into common and unique components, it was necessary to have multiple indicators of the different scales. To satisfy this requirement, items in the scales were used to form parcels. Parcels are sums or averages of subsets of items used as indicators of a latent variable. Parceling has been widely discussed in methodological research (e.g., Little, Cunningham, Shahar, \& Widaman, 2002), the consensus being that parceling is the preferred choice when using data from multi-item scales with less than perfect reliability (which is most of the time). ${ }^{3}$ For the impression management scales, we randomly assigned items to one of three parcels. Each parcel was formed by averaging the items that were randomly assigned to it. These three parcel scores were then used as measured indicators of the latent variable.

For Studies 1 and 2 we included covariates to predict both denial and impression management. In Study 1, duration of employment as a temporary employee, scored in weeks, was included as a covariate predicting both denial of incompetence and impression management. Duration was divided by 100 to render its scale comparable with that of other variables in the model and to reduce the chance of convergence errors. In Study 2, age was included as a covariate in a similar manner.

\section{The Model}

The primary hypothesis was that the correlation between denial of incompetence and impression management would be stronger among threatened than among nonthreatened participants. Thus, a two-group structural equation model was specified to account for observed covariances separately within each group. The general form of the model is illustrated in Figure 2 (in Studies 3 and 4 there was no covariate, and thus no $\gamma_{1}$ and $\gamma_{2}$ parameters, but the structure of the model was otherwise the same).

In Study 1, the primary goal of the SEM analyses was to test the null hypothesis of equality of the partial correlation (controlling for duration) between denial of incompetence and impression management $\left(\phi_{r D E N, \text { rIMP }}\right)$ across the two groups. Using a method described by Little (1997), we specified the latent variables as rescaled phantom variables with unit variances so that the relationship between denial of incompetence and impression management could be represented as a partial correlation rather than as a partial covariance.

Model testing proceeded according to a three-step strategy. First, the model depicted in Figure 2 was estimated simultaneously in both threat groups without cross-group parameter constraints (the no-constraint model). This step allows the evaluation of the overall fit of the general model structure.

An additional benefit of the procedure described by Little (1997) is that it permits establishing whether weak factorial (measurement) invariance holds across groups, which in turn permits cross-group comparison of key parameters. Demonstrating weak factorial invariance is accomplished by constraining factor loadings to equality across groups and noting a nonsignificant increase in the overall $\chi^{2}$ statistic. Therefore, the second step was to constrain factor loadings to equality across groups (the loadingconstrained model). Only after measurement invariance has been established can the cross-group equivalence of $\phi_{r D E N, r I M P}$ be addressed (the $r$-constrained model).

\section{Modeling Results}

Means, standard deviations, and correlations of the measured variables and parcels for Study 1 can be found in Table 1. Results for each step of the model testing are contained in Table 2. The fit of the no-constraint model was excellent, $\chi^{2}(8, N=114)=7.206$, $p=.515$, root-mean-square error of approximation (RMSEA) $=$

\footnotetext{
${ }^{3}$ The alternatives to parceling are to use individual items as indicators, which unnecessarily decreases model parsimony and creates unwanted sources of spurious covariation among items or to rely on scale scores, which precludes the use of latent variables and the correction for unreliability (Coffman \& MacCallum, in press). Failure to use parcels in the presence of measurement error can lead to identification problems and improper solutions (Ding, Velicer, \& Harlow, 1995).
} 
(1)

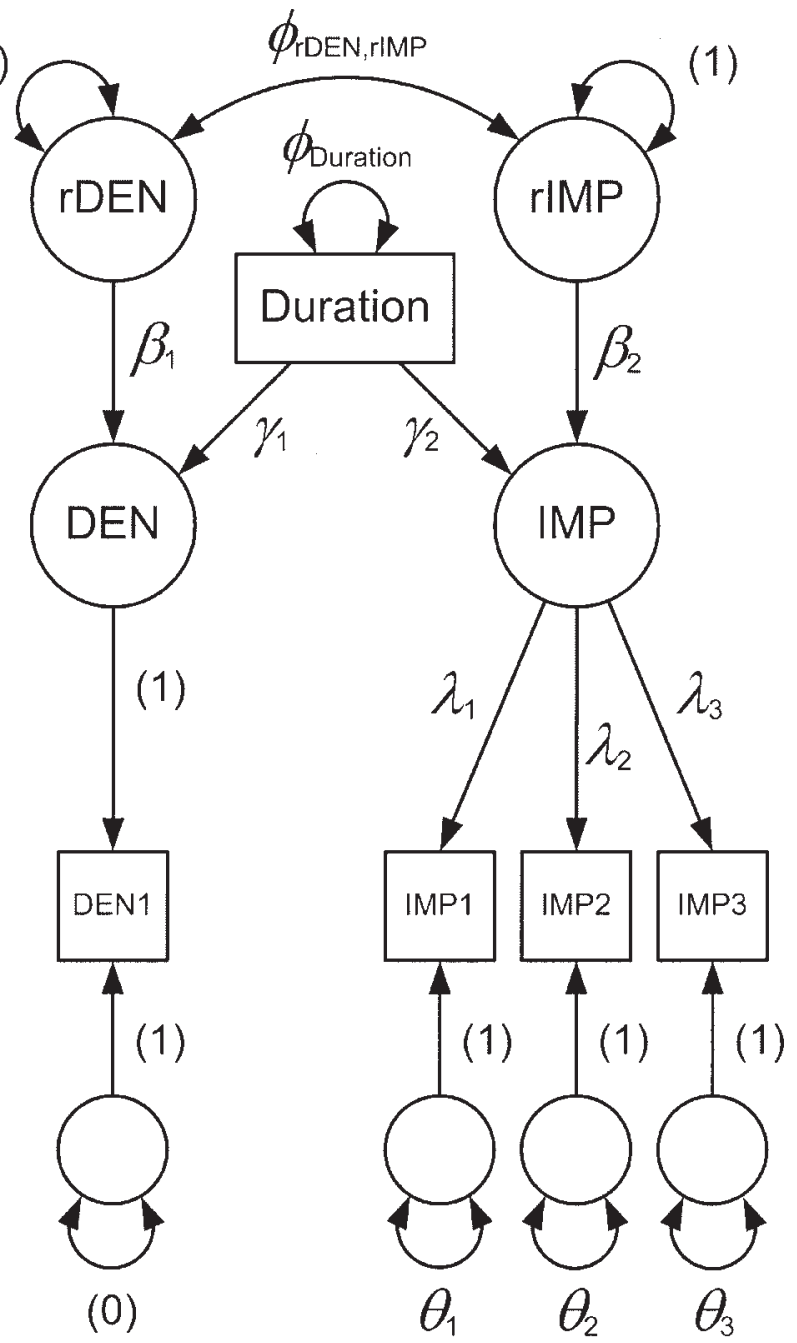

Figure 2. Path diagram of model used in each group in Study 1. The parameters $\beta_{1}$ and $\beta_{2}$ represent standard deviations of the partialed latent variables, $\phi_{\text {Duration }}$ represents the variance of the duration covariate, $\gamma_{1}$ and $\gamma_{2}$ represent the unstandardized regression weights of denial of incompetence (DEN) and impression management (IMP) on duration, and $\theta_{1-3}$ represent unique variances associated with impression management parcels. $\mathrm{rDEN}=$ residual associated with denial of incompetence; $\mathrm{rIMP}=$ residual associated with impression management; $\lambda_{1-3}=$ factor loadings for the IMP factor; DEN1 = single indicator for the DEN factor; IMP1-3 = indicators (parcels) for the IMP factor.

$.000(.000, .146)$, MSRMR $^{4}=.050$. The small $\chi^{2}$ and wide confidence interval for RMSEA could be due to the small sample size used in Study 1, but the small MSRMR indicates that the model is adequately reproducing observed covariances. The fit of the loading-constrained model was likewise excellent, $\chi^{2}(10)=$ $9.400, p=.495$, RMSEA $=.011(.000, .138)$, MSRMR $=.063$. A $\chi^{2}$-difference test reveals that the loading-constrained model does not fit significantly worse than the no-constraint model, $\Delta \chi^{2}(2)=2.194, p=.334$, indicating that weak factorial invariance holds and allowing cross-group comparison of correlations. The correlation between denial of incompetence and impression management in the no threat group was only $\phi_{r D E N, r I M P}=.076$
$(90 \% \mathrm{CI}=-.238, .381 ; n s),{ }^{5}$ whereas $\phi_{r D E N,}$ rIMP $=.541(90 \%$ $\mathrm{CI}=.211, .794$; significant) in the threat group. Constraining these correlations to equality across groups resulted in a significant decrease in fit, $\chi^{2}(11)=13.676, p=.251$, RMSEA $=.066(.000$, $.164)$, MSRMR $=0.088$, indicating that the correlations are significantly different across groups $\Delta \chi^{2}(1)=4.276, p=.039$.

For the sake of brevity, the modeling results are only presented for Study 1, but the results of Studies 2-4 followed the same pattern, with good fit of the initial models, support for weak factorial invariance, and a significant decrease in fit when the key parameters were constrained to equality. ${ }^{6}$

\section{General Discussion}

The results of four studies provide support for the hypothesis that some people cope with stereotype threat with denial: Participants high in impression management concerns were most likely to deny incompetence if they were acutely or chronically threatened by a stereotype of incompetence. In Study 1 temporary employees who were concerned about impression management responded to manipulated stereotype threat by denying self-doubt. In Study 2 institutionalized older adults who were concerned about impression management responded to chronic stereotype threat by denying cognitive failures. In Study 3 , African American students who were high in impression management concerns responded to chronic stereotype threat by claiming they were intelligent, particularly if they had attended a predominantly Black high school and were tested by a White experimenter. In Study 4 White students who were high in impression management concerns responded to manipulated stereotype threat by denying the importance of being intelligent.

The consistency of these results across such a wide variety of populations and domains suggests that stereotype threat is aversive in part because it diminishes the self in the eyes of others. The fact that people who are concerned with impression management responded with denial indicates that rather than acquiescing to the perceived stereotypic impressions of others, they are instead attempting to resist these impressions and foster a more positive image. Such a concern with the perceptions of others is a hallmark of impression management, and the current findings extend previous research by demonstrating that stereotype threat focuses this concern on the implications of the stereotype for others' impressions. In an attempt to manage these impressions, people high in impression management respond to stereotype threat by denying the stereotype and bolstering their claims to competence.

\footnotetext{
${ }^{4}$ We used a multiple-group extension of the standardized root-meansquared residual (SRMR; Jöreskog \& Sörbom, 1996), a residual-based fit index relatively immune to sample size. Hu and Bentler (1999) recommend that a cutoff value close to .08 be chosen when SRMR is used in isolation, although a value closer to .09 seems more appropriate when used in conjunction with other fit indices. The multiple-group version of SRMR (MSRMR also implemented in the software package Mplus; Muthén, 1998-2004) weights the group SRMRs by sample size prior to summation. The Mx code for computing MSRMR is available on request from Kristopher J. Preacher.

${ }^{5} \mathrm{Mx}$ uses maximum-likelihood optimization to compute asymmetric confidence intervals, which have better statistical properties than the usual standard-error-based intervals (Neale et al., 2003).

${ }^{6}$ These models are available on request from Kristopher J. Preacher.
} 
Table 1

Means, Standard Deviations, and Correlations Among Duration, Denial, and the Impression Management Parcels in Study 1

\begin{tabular}{|c|c|c|c|c|c|}
\hline Variable & 1 & 2 & 3 & 4 & 5 \\
\hline \multicolumn{6}{|c|}{ No-threat group } \\
\hline 1. Dur100 & 1.1710 & & & & \\
\hline 2. Denial & .2813 & .9354 & & & \\
\hline 3. Imp1 & .1596 & .0612 & .3638 & & \\
\hline 4. Imp2 & .0507 & .1652 & .4571 & .4044 & \\
\hline 5. Imp3 & .1963 & -.0261 & .3081 & .1784 & .4272 \\
\hline$M$ & 0.8580 & 4.0000 & 2.5026 & 2.1744 & 1.9436 \\
\hline \multicolumn{6}{|c|}{ Threat group } \\
\hline 1. Dur100 & 1.2622 & & & & \\
\hline 2. Denial & .0811 & 1.0173 & & & \\
\hline 3. Imp1 & -.0723 & .2557 & .3792 & & \\
\hline 4. Imp2 & .2036 & .4056 & .3474 & .3668 & \\
\hline 5. Imp3 & .1344 & .2800 & .3427 & .3586 & .4249 \\
\hline$M$ & 0.8402 & 3.9184 & 2.5170 & 2.1497 & 1.9524 \\
\hline
\end{tabular}

Note. Standard deviations are on the diagonals. Dur $100=$ duration in weeks divided by $100 ;$ Denial $=$ denial of incompetence; Imp1-3 = impression management.

This sort of resistance may be critical in preventing the stereotype from creating its own reality, but it also appears to be rather fragile, as participants in Study 4 shifted to a strategy of denying domain importance when they believed they would have to per-

Table 2

Key Parameter Estimates in the No-Constraint, LoadingConstrained, and r-Constrained Models in Study 1

\begin{tabular}{llll} 
& \multicolumn{3}{c}{ Model } \\
\cline { 2 - 4 } Parameter & No-constraint & Loading-constrained & $r$-constrained \\
\hline
\end{tabular}

\begin{tabular}{lccc}
\hline \multicolumn{3}{c}{ No-threat group } \\
$\phi_{\text {rDEN, rIMP }}$ & 0.043 & 0.076 & $0.287^{\mathrm{a}}$ \\
$\phi_{\text {Duration }}$ & $1.371^{\mathrm{a}}$ & $1.371^{\mathrm{a}}$ & $1.371^{\mathrm{a}}$ \\
$\beta_{1}$ & $0.898^{\mathrm{a}}$ & $0.898^{\mathrm{a}}$ & $0.915^{\mathrm{a}}$ \\
$\beta_{2}$ & $(1.000)$ & $(1.000)$ & $(1.000)$ \\
$\gamma_{1}$ & $0.225^{\mathrm{a}}$ & $0.225^{\mathrm{a}}$ & $0.225^{\mathrm{a}}$ \\
$\gamma_{2}$ & 0.168 & 0.183 & 0.177 \\
$\lambda_{1}$ & $0.303^{\mathrm{a}}$ & $0.237^{\mathrm{a}}$ & $0.233^{\mathrm{a}}$ \\
$\lambda_{2}$ & $0.212^{\mathrm{a}}$ & $0.248^{\mathrm{a}}$ & $0.258^{\mathrm{a}}$ \\
$\lambda_{3}$ & $0.153^{\mathrm{a}}$ & $0.197^{\mathrm{a}}$ & $0.194^{\mathrm{a}}$ \\
\hline
\end{tabular}

\begin{tabular}{lccc}
\hline \multicolumn{3}{c}{ Threat group } \\
$\phi_{\text {rDEN, rIMP }}$ & $0.543^{\mathrm{a}}$ & $0.541^{\mathrm{a}}$ & $0.287^{\mathrm{a}}$ \\
$\phi_{\text {Duration }}$ & $1.593^{\mathrm{a}}$ & $1.593^{\mathrm{a}}$ & $1.593^{\mathrm{a}}$ \\
$\beta_{1}$ & $1.014^{\mathrm{a}}$ & $1.014^{\mathrm{a}}$ & $0.990^{\mathrm{a}}$ \\
$\beta_{2}$ & $(1.000)$ & $0.973^{\mathrm{a}}$ & $0.956^{\mathrm{a}}$ \\
$\gamma_{1}$ & 0.065 & 0.065 & 0.065 \\
$\gamma_{2}$ & 0.160 & 0.129 & 0.133 \\
$\lambda_{1}$ & $0.183^{\mathrm{a}}$ & $0.237^{\mathrm{a}}$ & $0.233^{\mathrm{a}}$ \\
$\lambda_{2}$ & $0.257^{\mathrm{a}}$ & $0.248^{\mathrm{a}}$ & $0.258^{\mathrm{a}}$ \\
$\lambda_{3}$ & $0.226^{\mathrm{a}}$ & $0.197^{\mathrm{a}}$ & $0.194^{\mathrm{a}}$ \\
\hline
\end{tabular}

Note. Italicized numbers in parentheses are parameters fixed to indicated values for model identification reasons.

${ }^{\text {a }}$ Significant at least at the $\alpha=.05$ level. form in the stereotyped domain. In contrast to stereotype denial, denial of importance appears to be an acquiescent strategy, in which people acknowledge that the stereotype may well describe their behavior, but proactively cope with this possibility by claiming that they do not care.

Although all four studies provide evidence that people respond to stereotype threat with denial, all four studies also provided evidence that not all individuals respond in this manner. Rather than causing everyone to deny incompetence, stereotype threat appears to lead to selective use of this strategy among those who are particularly concerned with impression management. This selectivity in which individuals show denial opens the question of what strategy is adopted by those who are low in impression management. There was no evidence in the current research regarding strategies specifically engaged in by these individuals, but they might engage in a host of other coping strategies that are less self-presentational in nature. For example, individuals low in impression management might experience stereotype threat as an intrapersonal problem, with which they cope more by reassuring themselves (e.g., by reminding themselves of past successes) than by reassuring others.

\section{Coping and Performance}

The current research documented the use of stereotype denial across a variety of domains, but it also revealed that this coping mechanism was not associated with performance deficits. In combination with the finding that only a subset of individuals relies on denial, these results raise the question of what other coping mechanisms might exist and which of these might be implicated in performance deficits. One possible coping mechanism can be found in research on identity bifurcation, or the process of disavowing traits that are perceived to be inconsistent with good performance in the stereotyped domain (e.g., femininity and math competence, see Pronin, Steele, \& Ross, 2004). This coping mechanism seems to predict the ability to maintain high standards of 
performance over the long term, as identity bifurcation is only exhibited by people who are highly identified with the stereotyped domain. Identity bifurcation appears to be unrelated to acute performance deficits, however, as these highly identified individuals are the very ones most likely to show performance disruptions under stereotype threat (Steele et al., 2003).

There is also suggestive evidence for another method of coping with stereotype threat that might be considered the internal analog of denial, specifically, suppression of stereotype threat related thoughts. That is, rather than denying the stereotype by claiming competence, people may simply suppress thoughts of stereotype threat and attempt to focus their attention on the task at hand. Such a strategy of inhibition need not be conscious, as evidence suggests that people spontaneously inhibit thoughts of certain aspects of the self when confronted with the potential for internal incongruency (Hugenberg \& Bodenhausen, 2004). If inhibition of stereotype threat is an effective coping strategy it might be associated with attenuated performance deficits, as this strategy would effectively remove the threat of the stereotype by removing thoughts of it from consciousness. Whether inhibiting thoughts of stereotype threat is an effective coping strategy remains to be adequately tested, but preliminary evidence suggests that women who have better inhibitory ability show reduced performance deficits on a driving simulator when under threat of the stereotype that they are poor drivers (C. von Hippel, Yeung, Zouroudis, \& Walsh, 2005). One interpretation of this finding is that women with good inhibitory skills successfully keep the stereotype out of mind so that they can focus on the driving task in which they are engaged.

Finally, the possibility remains that performance deficits associated with stereotype threat are in fact an ironic consequence of coping strategies that people adopt when they feel threatened. Perhaps it is their efforts to prove that the stereotype is not true, or to restore their damaged sense of self-worth, or to bolster their confidence, or simply to determine whether their reputation is at risk, that causes stereotype threatened people to suffer deficits in working memory (Schmader \& Johns, 2003) and a disruptive mental load (Croizet et al., 2004). Consideration of such avenues for coping with stereotype threat and their consequences may be a worthwhile goal for future research.

\section{Exploiting Disruptions in Self-Report}

The findings of the current research open the door to a new methodology for studying stereotype threat. To the extent that stereotype threat disrupts the self-report of ability in a manner demonstrated in Studies 1-3, the current procedure provides a technique whereby it should be possible to assess stereotype threat via survey research by searching for this disruption. Such a possibility would facilitate the measurement of stereotype threat outside the laboratory, thereby enabling a more complete assessment of the populations that are impacted by it and the degree to which people's everyday lives are affected (for a discussion of how survey research can complement an experimental approach, see Visser, Krosnick, \& Lavrakas, 2000).

The current method has all the advantages of self-report, and yet does not require that participants have introspective insight into the experiences that they find threatening. It seems unlikely that participants in the current experiments would have been willing or able to report the threat associated with cognitive incompetence, as doing so would itself be threatening. Thus, an important feature of the current research was that neither ability nor willingness to recognize stereotype threat was necessary to document its effects on self-report measures. Instead of asking participants whether the stereotype of incompetence was threatening, the current research exploited the idea that as the possibility of incompetence becomes increasingly threatening, self-reports concerning incompetence should become increasingly sensitive to impression management concerns. Thus, rather than being viewed as an unfortunate source of error in self-report data, the current research demonstrates how the observation of impression management concerns may offer insights into coping processes associated with stereotype threat.

\section{References}

Arkin, R. M., \& Oleson, K. C. (1998). Self-handicapping. In J. M. Darley \& J. Cooper (Eds.), Attribution and social interaction: The legacy of Edward E. Jones (pp. 313-371). Washington, DC: American Psychological Association.

Arnold, H. J. (1982). Moderator variables: A clarification of conceptual, analytic, and psychometric issues. Organizational Behavior and Human Performance, 29, 143-174.

Brewer, M. B., Dull, V., \& Lui, L. (1981). Perceptions of the elderly: Stereotypes as prototypes. Journal of Personality and Social Psychology, 41, 656-670.

Broadbent, D., Cooper, P., Fitzgerald, P., \& Parkes, K. (1982). The cognitive failures questionnaire and its correlates. British Journal of Clinical Psychology, 21, 1-16.

Cadinu, M., Maass, A., Frigerio, S., Impagliazzo, L., \& Latinotti, S. (2003). Stereotype threat: The effect of expectancy on performance. European Journal of Social Psychology, 33, 267-285.

Coffman, D. L., \& MacCallum, R. C. (in press). Using parcels to convert path analysis models into latent variable models. Multivariate Behavioral Research.

Crocker, J., \& Major, B. (1989). Social stigma and self-esteem: The selfprotective properties of stigma. Psychological Review, 96, 608-630.

Croizet, J.-C., Despres, G., Gauzins, M.-E., Huguet, P., Leyens, J.-P., \& Meot, A. (2004). Stereotype threat undermines intellectual performance by triggering a disruptive mental load. Personality and Social Psychology Bulletin, 30, 721-731.

Crosby, F. (1982). Relative deprivation and working women. New York: Oxford University Press.

Crosby, F. (1984). The denial of personal discrimination. American Behavioral Scientist, 27, 371-386.

Crowne, D. P., \& Marlowe, D. (1960). A new scale of social desirability independent of psychopathology. Journal of Consulting Psychology, 24, $349-354$.

Ding, L., Velicer, W. F., \& Harlow, L. L. (1995). Effects of estimation methods, number of indicators per factor, and improper solutions on structural equation modeling fit indices. Structural Equation Modeling, 2, 119-144.

Ditto, P. H., \& Lopez, D. A. (1993). Motivated skepticism: Use of differential decision criteria for preferred and nonpreferred conclusions. Journal of Personality and Social Psychology, 63, 568-584.

Ford, T. E., Ferguson, M. A., Brooks, J. L., \& Hagadone, K. M. (2004). Coping sense of humor reduces effects of stereotype threat on women's math performance. Personality and Social Psychology Bulletin, 30, 643-653.

Gallagher, D. G., \& McLean Parks, J. (2001). The contemporary work environment. Human Resources Management Review, 11, 181-208.

Gleason, S. E. (in press). The shadow workforce. East Lansing, MI: Michigan State University Press.

Hess, T., Auman, C., Colcombe, S. J., \& Rahhal, T. A. (2003). The impact 
of stereotype threat on age differences in memory performance. Journals of Gerontology: Series B: Psychological Sciences \& Social Sciences, $58 B, 3-11$.

Hu, L.-T., \& Bentler, P. M. (1999). Cutoff criteria for fit indexes in covariance structure analysis: Conventional criteria versus new alternatives. Structural Equation Modeling, 6, 1-55.

Hugenberg, K., \& Bodenhausen, G. V. (2004). Category membership moderates the inhibition of social identities. Journal of Experimental Social Psychology, 40, 233-238.

Jöreskog, K. G., \& Sörbom, D. (1996). LISREL 8 user's reference guide. Chicago: Scientific Software International.

Keller, J. (2002). Blatant stereotype threat and women's math performance: Self-handicapping as a strategic means to cope with obtrusive negative performance expectations. Sex Roles, 47, 193-198.

Keller, J., \& Dauenheimer, D. (2003). Stereotype threat in the classroom: Dejection mediates the disrupting threat effect on women's math performance. Personality and Social Psychology Bulletin, 29, 371-381.

Kuiper, N. A., Martin, R. A., \& Olinger, L. J. (1993). Coping humor, stress, and cognitive appraisals. Canadian Journal of Behavioural Science, 25, $81-96$.

Lakin, J., \& Arkin, R. (2005). Impression management and claimed competence. Unpublished manuscript, Drew University.

Levy, B. (1996). Improving memory in old age through implicit selfstereotyping. Journal of Personality and Social Psychology, 71, 10921107.

Levy, B., Hausdorff, J. M., Hencke, R., \& Wei, J. Y. (2000). Reducing cardiovascular stress with positive self-stereotypes of aging. Journals of Gerontology: Psychological Sciences \& Social Sciences, 55B, 205-213.

Little, T. D. (1997). Mean and covariance structures (MACS) analyses of cross-cultural data: Practical and theoretical issues. Multivariate Behavioral Research, 32, 53-76.

Little, T. D., Cunningham, W. A., Shahar, G., \& Widaman, K. (2002). To parcel or not to parcel: Exploring the question, weighing the merits. Structural Equation Modeling, 9, 151-173.

MacCallum, R. C., Zhang, S., Preacher, K. J., \& Rucker, D. D. (2002). On the practice of dichotomization of quantitative variables. Psychological Methods, 7, 19-40.

Major, B., Quinton, W. J., McCoy, S. K., \& Schmader, T. (2000). Reducing prejudice: The target's perspective. In S. Oskamp (Ed.), Reducing prejudice and discrimination (pp. 211-238). Mahwah, NJ: Erlbaum.

Major, B., \& Schmader, T. (1998). Coping with stigma through psychological disengagement. In J. K. Swim \& C. Stangor (Eds.), Prejudice: The target's perspective (pp. 191-218). San Diego: Academic Press.

Markus, H., \& Wurf, E. (1987). The dynamic self-concept: A social psychological perspective. Annual Review of Psychology, 38, 299-337.

Miller, C. T., \& Kaiser, C. R. (2001). A theoretical perspective on coping with stigma. Journal of Social Issues, 57, 73-92.

Miller, C. T., Rothblum, E. D., Felicio, D., \& Brand, P. (1995). Compensating for stigma: Obese and nonobese women's reactions to being visible. Personality \& Social Psychology Bulletin, 21, 1093-1106.

Muthén, B. O. (1998-2004). Mplus technical appendices. Los Angeles: Muthén \& Muthén.

Neale, M. C., Boker, S. M., Xie, G., \& Maes, H. H. (2003). Mx: Statistical modeling (6th ed.) [Computer software and manual]. Richmond, VA: Virginia Commonwealth University, Department of Psychiatry. Retrieved April 15, 2004, from http://www.vcu.edu/mx/

Nelson, L. J., \& Miller, D. T. (1995). The distinctiveness effect in social categorization: You are what makes you unusual. Psychological Science, 6, 246-249.

Paulhus, D. L. (1991). Measurement and control of response bias. In J. P. Robinson, P. R. Shaver, \& L. S. Wrightsman (Eds.), Measures of personality and social psychological attitudes. San Diego: Academic Press.

Paulhus, D. L., \& Reid, D. (1991). Enhancement and denial in socially desirable responding. Journal of Personality and Social Psychology, 60, 307-317.

Polivka, A. E. (1996). A profile of contingent workers. Monthly Labour Review, October, 10-21.

Pronin, E., Steele, C. M., \& Ross, L. (2004). Identity bifurcation in response to stereotype threat: Women and mathematics. Journal of Experimental Social Psychology, 40, 152-168.

Raven, J. C., Court, J. H., \& Raven, J. (1985). Manual for Raven's Advanced Progressive Matrices and Vocabulary Scales: General overview. London, England: H. K. Lewis.

Rogers, J. K. (1995). Just a temp: Experience and structure of alienation in temporary clerical employment. Work and Occupations, 22, 137-160.

Ruggiero, K. M., \& Taylor, D. M. (1997). Why minority group members perceive or do not perceive the discrimination that confronts them: The role of self-esteem and perceived control. Journal of Personality and Social Psychology, 72, 373-389.

Schimel, J., Arndt, J., Banko, K. M., \& Cook. A. (2004). Not all selfaffirmations were created equal: The cognitive and social benefit of affirming the intrinsic (vs. extrinsic) self. Social Cognition, 22, 75-99.

Schmader, T., \& Johns, M. (2003). Converging Evidence That Stereotype Threat Reduces Working Memory Capacity. Journal of Personality and Social Psychology, 85, 440-452.

Spencer, S. J., Steele, C. M., \& Quinn, D. M. (1999). Stereotype threat and women's math performance. Journal of Experimental and Social Psychology, 35, 4-28.

Steele, C. M. (1997). "A threat in the air": How stereotypes shape intellectual identity and performance. American Psychologist, 52, 613-629.

Steele, C. M., \& Aronson, J. (1995). Stereotype threat and the intellectual test performance of African Americans. Journal of Personality and Social Psychology, 69, 797-811.

Steele, C. M., Spencer, S. J., \& Aronson, J. (2003). Contending with group image: The psychology of stereotype and social identity threat. In M. P. Zanna (Ed.), Advances in experimental social psychology (pp. 102-115). San Diego: Academic Press.

Stone, J. (2002). Battling doubt by avoiding practice: The effects of stereotype threat on self-handicapping in white athletes. Personality and Social Psychology Bulletin, 28, 1667-1678.

Tesser, A., \& Paulhus, D. L. (1983). The definition of self: Private and public self-evaluation management strategies. Journal of Personality and Social Psychology, 44, 672-682.

Visser, P. S., Krosnick, J. A., \& Lavrakas, P. J. (2000). Survey research. In H. T. Reis \& C. M. Judd (Eds.), Handbook of research methods in social and personality psychology (pp. 223-252). New York: Cambridge University Press.

von Hippel, C., Mangum, S. L., Greenberger, D. B., Heneman, R. L., \& Skoglind, J. D. (1997). Temporary employment: Can organizations and employees both win? The Academy of Management Executive, 11 93-104.

von Hippel, C., Yeung, J., Zouroudis, A., \& Walsh, A. (2005). Stereotype threat in the real world. Paper presented at the 34th annual meeting of the Society for Australasian Social Psychology, Townsville, Queensland.

von Hippel, W., Hawkins, C., \& Schooler, J. W. (2001). Stereotype distinctiveness: How counter-stereotypic behavior shapes the selfconcept. Journal of Personality and Social Psychology, 81, 193-205.

Wilson, T. D., Wheatley, T., Kurtz, J., Dunn, E., \& Gilbert, D. T. (2004). When to fire: Anticipatory versus post-event reconstrual of uncontrollable events. Personality and Social Psychology Bulletin, 30, 340-351. Zachary, R. A. (1986). Shipley Institute of Living Scale (Revised). Los Angeles: Western Psychological Services.

Received June 25, 2004 Revision received February 18, 2005 Accepted March 23, 2005 